\title{
Variability in the shelf life of table grapes from same batch when exposed under different ambient air conditions
}

\author{
Cíntia Carla Melgaço de OLIVEIRA ${ }^{1 *}$ (D), Davi Rocha Bernardes de OLIVEIRA ${ }^{1}$, Vivaldo SILVEIRA JUNIOR ${ }^{1}$
}

\begin{abstract}
This study aimed to evaluate the effect of the variability in ambient air conditions (temperature and relative humidity) and periods of exposure on the same batch of table grapes in the first stages of the fruit supply chain (harvesting, processing and storage prior to commercialization), in order to predict their dynamic shelf life. To estimate the shelf life we used a linear prediction model dependent on time and ambient air conditions (temperature and relative humidity). It was noted that during processing, there was considerable variations in ambient air conditions that grapes were exposed to, especially in harvesting stage. The ambient of following stages showed homogeneity in air conditions, but the residence time and the way of palletizing grapes affected their shelf life. We observed heterogeneity in the shelf life among different grape pallets and among boxes on a same pallet, with variations of up to 34 days. Thus, we ascertained a heterogeneity in the quality of table grapes from the same production batch, due to the variability in ambient air conditions and period of exposure, which should be considered in the logistics management of the dynamic shelf life of the product in the cold chain.
\end{abstract}

Keywords: environmental conditions; monitoring; dynamic shelf life; quality heterogeneity; predictive model, FEFO.

Practical Application: Perishable products shelf life is dynamic and dependent on ambient conditions.

\section{Introduction}

Losses and waste in the various stages of the food supply chain are significant in the global scenario. At global level, about one third of food for human consumption is lost or wasted annually, which corresponds to 1.3 billion tons of food or, in monetary value, about US\$ 1 trillion a year. This amount could feed about 2 billion people (Benítez, 2018). All these products would be more than enough to extinguish world food insecurity. In other words, the world food production, without losses and wastes, would be more than enough for all human consumption. The impacts caused by food losses and waste are not restricted to economical and ethical ones. They also result in major environmental and public health impacts. A large part of this occurs because many supply chains of perishable products are operating in a "below ideal" condition, especially regarding fresh fruits and vegetables, which have a shorter shelf life than canned and frozen products (Badia-Melis et al., 2018).

In this context, it is clear that reducing food losses and waste should be a global priority. In 2015, the United Nations (UN) established the new Sustainable Development Goals (SDG's), which are based on the based on the eight Millennium Development Goals (MDG's). The target number 12.3 of the document states that countries should commit themselves to halve global per capita waste by 2030 , at the retail and consumer levels. This target also aims to reduce food losses along the production and supply chains, including post-harvest losses (United Nations, 2015).
Two major obstacles are need to be addressed to achieve the SDG's, including the lack of actual country-level information on losses and food waste, and the difficulty of accessing to technical information on supply chains. To overcome these challenges, actions are needed in order to identify and establish efficient actions to remedy the bottlenecks in each stage of the supply chain (WRI Brasil, 2017). The second obstacle to achieve SDG goal 12.3 is the lack of awareness of food waste earlier than the final stages of supply chain. Retailers and final consumers should have access to a high quality product with a longer shelf life. To do this, it is necessary to improve the efficiency of the supply chain before the retail stage, by investing in infrastructure and logistics and, especially, by increasing knowledge of the integration among all stages (EMBRAPA, 2018).

One way to reduce losses and increase product shelf life is to implement efficient logistics that take into account product quality. Several countries are implementing reforms in perishable goods logistics, replacing the FIFO method (First In, First Out) with FEFO (First Expired, First Out). In this method, stock is rotated to ensure that the shelf life of each product is adjusted to the storage period and to ambient air conditions of the remaining stages. Researchers have reported the advantages of applying the FEFO method to the cold chain, such as quality losses of meat decreased from 16 to $8 \%$ and of fish from 15 to 5\% (Jedermann et al., 2009); strawberry losses at the distribution center decreased from 37 to 23\% (Nunes et al., 2014). The English

${ }^{1}$ Laboratório de Automação e Controle de Processos de Alimentos - LACPA, Departamento de Engenharia de Alimentos, Faculdade de Engenharia de Alimentos, Universidade Estadual de Campinas, Campinas, SP, Brasil

*Corresponding author: cintiamelgaco@hotmail.com, cintiaea@unicamp.br 
company BT9 achieved savings of US $\$ 400,000$ in cherry shipping after implementing this method (BT9, 2018).

Application of the FEFO method to the food sector is not a trivial undertaking, despite advances in recent years. Efficient logistics with minimization of losses and waste requires increasing the number of measurements to ensure proper monitoring, as well as ensuring accurate, frequent and automated measurements interpreted by software and coordinated with inventories of existing and planned products (Ruiz-Garcia \& Lunadei, 2010). The wireless sensor network (WSN) is one of the promising technologies for monitoring cold chain environments (Aung \& Chang, 2014; Badia-Melis et al., 2018; Cuiñas et al., 2014; Jedermann et al., 2014b; Kim et al., 2015). Although the elevated cost is still a barrier to its implementation (Badia-Melis et al., 2018), some studies show that radio frequency identification (RFID) technologies can reduce energy consumption and provide economical solutions for wireless communication (Zou et al., 2014).

In addition to an adequate data collection system, the application of the FEFO method requires a mathematical model that predicts the shelf life of the product, which is its remaining lifetime before rejection by consumers. Shelf life cannot be measured directly, as it depends on the product exposure to environmental conditions. In this way, this parameter should be treated as a dynamic variable, and not as a constant determined by suitable fixed processing and storage conditions. Thereby, the product dynamic shelf life can be defined as the difference between its maximum lifetime (if stored in ideal conditions) and the accumulated loss of a determined quality parameter (mass loss, $\mathrm{pH}$, color, etc.), which may vary depending on the actual exposure conditions.

Temperature is the most important factor in extending or maintaining the shelf life of perishable products which, associated with time, dictates their freshness (Aung \& Chang, 2014; Todd, 2017). Despite this, it is currently observed the great inability to control/monitor the temperature in global supply networks. Temperature control in a cold chain can preserve products sensory, microbiological and nutritional qualities. An example of this is the loss of vitamin $\mathrm{C}$ in vegetables, which can be up to $10 \%$ per day when stored at a temperature of $2{ }^{\circ} \mathrm{C}$. Meanwhile, this loss can increase to more than $50 \%$ per day if they were stored at temperatures above $20^{\circ} \mathrm{C}$ (Badia-Melis et al., 2018).

Another factor of equal importance, which, associated with temperature, also influences the shelf life of the perishable product is the relative humidity $(\mathrm{RH})$ of the air to which the food is exposed (Badia-Melis et al., 2018). In environments with low relative humidity, an intensification of food water loss, and consequently mass loss, usually occurs, mainly in fresh and unpackaged products. In grapes, in addition to the loss of mass in commercialization, its appearance might also be depreciated by desiccation and browning of stems and pedicels (Holcroft, 2015). The critical level of mass loss resulting from perspiration, that causes it to be discarded, varies according to the grape variety. Some authors suggest a value of $5 \%$ of grapes initial mass (Crisosto \& Mitchell, 2002; Holcroft, 2015; Pereira et al., 2017). Furthermore, the optimum air temperature and relative humidity recommended for grapes conservation are about 0 to $2{ }^{\circ} \mathrm{C}$ and
85 to $95 \%$ respectively, resulting in shelf lives ranging from 56 to 180 days (Chitarra \& Chitarra, 2005).

Real-time monitoring of ambient air conditions and the development of models to estimate shelf life are important strategies for perishable food chain logistics, enabling proactive actions by managers to reduce financial losses (Jedermann et al., 2014a). The aim of this study regarding supply chain operation was to evaluate the effects of exposure time and ambient air on the variability of table grapes quality, to predict shelf life. In addition, this work presents data from several initial stages of table grapes cold chain, discussing details of the supply chain flow. This study allowed us to demonstrate the impacts of the period of exposure and ambient air conditions on the quality of bunches of table grapes.

\section{Material and methods}

\subsection{Monitoring the ambient air conditions during the storage of table grapes in the initial stages of the supply chain}

The cold chain of the Sweet Jubilee grape variety was monitored from the farm field to the cold storage room at different moments, including the packinghouse and cooling tunnel, using a combination of fixed and mobile temperature and humidity sensors accompanying the grapes during the first stages of the cold chain in a brazilian company. Fixed sensors were installed to assess the homogeneity of ambient air conditions and how this would affect the shelf life of the product according to its location in the environment. The ambient conditions of each stage in grapes processing was monitored during 8 days. Mobile sensors were used to quantify the exposure conditions and estimate the fruits' loss of mass, in order to predict their shelf life. Data acquisition of fixed and mobile sensors were made with a frequency of 30 minutes, except for harvest field, where data were collected every 1 hour. During the data acquisition, company conventional routine was carried out without external interference, in order to have a realistic overview or the entire logistic process. The grapes monitoring during their productive chain occurred for different periods in each beneficiation stage, according to the processing logistics carried out by the company. In this way, in this case report we worked with non-controllable assays, and, because of that, it was not possible to replicate grapes monitoring in each chain stage to apply statistical analysis.

\section{Harvesting}

Grapes harvesting occurred even in morning and afternoon, beginning at 7:00 a.m. and ending at 3:00 p.m., monitored by sensors installed in the field during eight consecutive days. During harvesting, grape bunches were collected and accommodated in plastic boxes. Each box was lined with a plastic blanket and filled with only one layer of grape bunches in order to prevent fruit crushing, totaling approximately $3 \mathrm{~kg}$ of grape in each of them. Three plastic boxes (labeled here as 1 , 2 and 3) were monitored in the afternoon (starting at 2:20 p.m.) and other two (labeled as 4 and 5) in the morning (starting at 8:20 a.m.), on consecutive days. All five boxes had temperature and humidity sensors installed on them. The monitoration of 
harvesting, packaging in plastic boxes and transportation to the packinghouse lasted approximately two hours.

\section{Packinghouse}

At the reception of the packinghouse, the ambient air was cooled by an adiabatic evaporative cooling system using water-soaked cooling pads (Sarntichartsak \& Thepa, 2013). While waiting for the selection, packaging and boxes palletizing stages, grape bunches within the harvest plastic boxes were acclimatized inside this ambient.

After reception, the table grape plastic boxes were directed to the selection and packing area. In this ambient, a selection was made and the grapes in bad conditions were removed. $500 \mathrm{~g}$ lots of the grape bunches in acceptable conditions were placed in plastic baskets, which were covered by perforated plastic film. Ten baskets were placed inside a cardboard box and the filled boxes were stacked on pallets, with 22 layers of cardboard boxes and five boxes in each layer. Pallets were tied with plastic tapes to prevent boxes from toppling over during transportation. Each monitored plastic boxes received from the harvesting was stacked in different pallet, forming the five of them, labeled as I, II, III, IV and V. In each pallet, there were installed six sets of temperature and relative humidity sensors in different positions, as shown in Figure 1. Four sensors were placed near the outside of the pallet in boxes A04, E04, C18 and D18, and two sensors were installed redundantly in box B11, near the inside center of the pallet. The two sensors were used together to increase measurement reliability at this critical position.

Inside packinghouse, pallets I, II and III were monitored for four hours, while pallets IV and V were monitored for approximately six hours. Despite of equal procedures, the differences in residence time among the pallets was due the processing/sales company logistics, in which we did not interfered at any time.

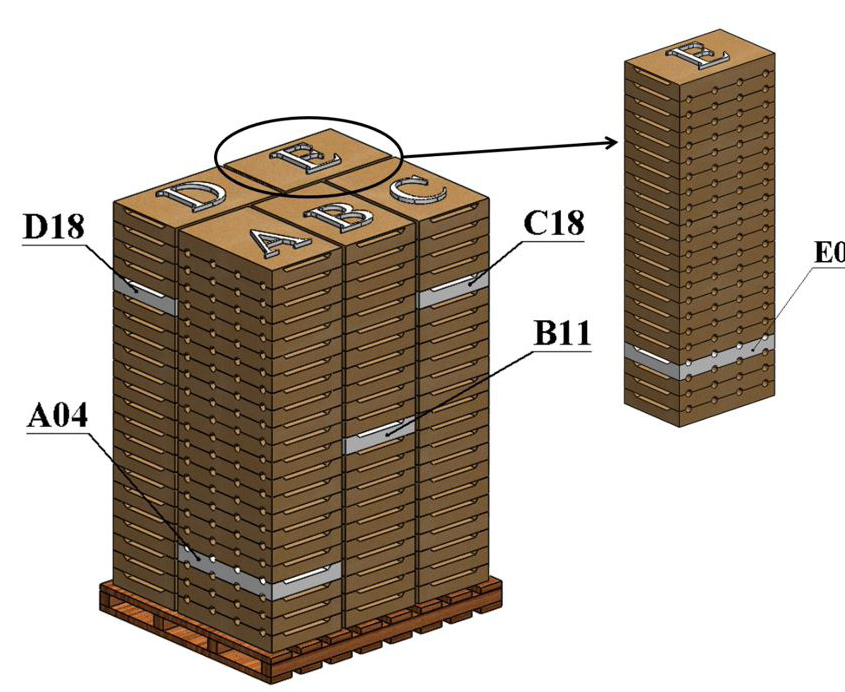

Figure 1. Positioning of sensors on the monitored pallets. Letters A to E represent the five stacked columns forming the pallet, while the numbers indicate box count from the bottom of the stack.
In addition to monitoring the environmental conditions during pallets formation, both packinghouse locations (reception, and selection and packaging) were also monitored using fixed sensors installed in all its extension during eight consecutive days.

\section{Cooling tunnel}

Following the company routine, the monitored pallets were sent to a Californian-type forced-air cooling tunnel to lower the temperature inside the grapes to $0{ }^{\circ} \mathrm{C}$ (Figure 2 ). The end of the cooling process was dictated by monitoring the temperature of randomly chosen grapes positioned within the top boxes, using insertion temperature sensors. Following the company routine, pallets I, II and III remained in cooling tunnel for nine hours, while the cooling process of pallets IV and V lasted 12 hours.

\section{Cold storage room}

After cooling, the monitored pallets were stored in cold storage rooms $(10.5 \times 19.0 \times 3.5 \mathrm{~m})$ awaiting transportation (Figure 3 ). Seven temperature and relative humidity sensors were installed in the room, in the following positions: one above the entrance door (S1) and another one between the two evaporators located on the opposite wall (S2); four on the side walls, two close to the ground level (S3 and S6) and two halfway up the room (S4 and S5); and at last, one right in the center of the room (S7). Monitoration of cold storage room ambient was performed for eight consecutive days. It should be noted that the duration of storage in the cold room varied according to the sales schedule, since destinations were not always determined immediately after packaging.

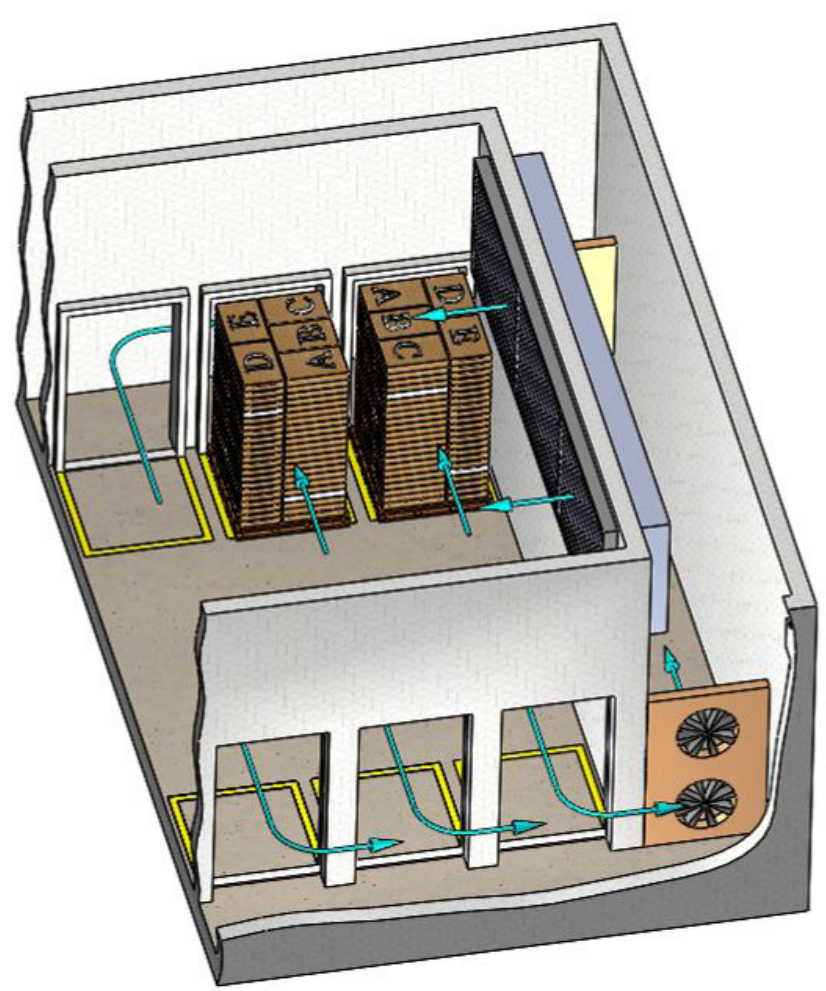

Figure 2. Partial view of the cooling tunnel. Blue arrows show the air direction leaving the evaporator and passing through the pallets. 


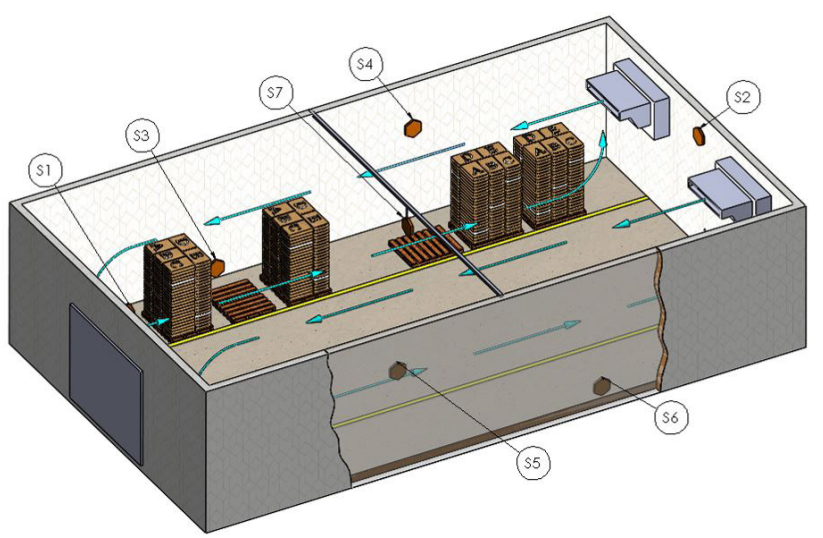

Figure 3. Schematic view of the cooling storage room. Blue arrows represent air direction leaving the evaporators. The highlighted hexagons represent the temperature and humidity sensors installed within the room.

According to the company's sales logistics, in which the harvested product did not always have a certain sale, the monitored pallets were stored for different times until their dispatch. In this way, pallet I remained stored in the cold room for 10 hours, while pallets II and III remained for 30 hours. Pallets IV and V remained stocked for approximately 103 hours.

\subsection{Monitoring system}

The ambient air conditions of the table grapes cold chain were monitored using Xsense ${ }^{\circledR}$ technology (BT9 Ltd., London, U.K.). The collected data and GPS locations were transmitted to a centralized (cloud) database.

\subsection{Calculation of weight loss and dynamic shelf life}

Grapes weight loss was estimated using algorithms that depends on the ambient air conditions, and the period of exposure of the product. The Equation 1 (Sastry \& Buffington, 1983), based on the solution for the stationary state of Fick first law, where there's a linear relation between the respective variables, was used to calculate the grapes weight loss. This model assumed the maximum availability of water vapor on the surface of the grape, i.e. saturation pressure at surface temperature.

$T T=k_{t}\left(P_{s}-P_{v}\right)$

where $T T$ is the rate of water loss from grape per weight unit of the product $\left(\mathrm{g} \mathrm{kg}^{-1} \mathrm{~h}^{-1}\right) ; P_{s}$ is the water saturation pressure on the surface of the grape $(\mathrm{Pa}) ; P_{v}$ is the ambient water vapor pressure $(\mathrm{Pa})$; and $k_{t}$ is the mass transfer integrated coefficient per mass unit of the product, and equal to $0.000443 \mathrm{~g} \mathrm{~kg}^{-1} \mathrm{~h}^{-1} \mathrm{~Pa}^{-1}$ for grapes in general (Sastry, Baird, \& Buffington, 1978). This value was used due to the lack of a specific coefficient for the Sweet Jubilee grape variety packaged in baskets and standard boxes.

The water vapor pressure at the evaporation surface, i.e. the water saturation pressure at a specific temperature, was estimated using the Antoine equation (Antoine, 1888) (Equation 2), while the ambient water vapor pressure was estimated using Equation 3. $\ln \left[P_{s}(T) \cdot 133,32^{-1}\right]=A-\left[B \cdot(T+C)^{-1}\right]$

$P_{v}=P_{s} \cdot(R H) \cdot 100^{-1}$

where $A, B$ and $C$ are Antoine equation coefficients. For water their values are $18.30,3816.44$ and -46.13 , respectively; $T$ is the air temperature, which was considered equal to the grape surface temperature (K); and $R H$ is the air relative humidity (\%).

The dynamic and cumulative weight loss of the grape bunches were estimated using Equation 4 (Leonardi et al., 1999).

$M_{f}=M_{o}-\sum\left(\dot{T T} \cdot M_{0} \cdot t \cdot 1000^{-1}\right)$

where $M_{f}$ and $M_{o}$ are the final and initial grape weight (g), respectively; and $t$ is the time of exposure of the grape to ambient air conditions (h).

Using Equation 4 we also calculated the shelf life of the fruit - that is, the time until it would be expected to be rejected by the consumer. For this, a maximum weight loss of $5 \%$ was considered as an acceptable quality limit for grapes (Crisosto \& Mitchell, 2002; Holcroft, 2015; Pereira et al., 2017), subsequently held under the best storage conditions $\left(0^{\circ} \mathrm{C}\right.$ and 95\% RH). We calculated how much longer it would take for the weight loss of the grapes to reach $5 \%$ of their initial weight, considering the cumulative water loss at each stage of the cold chain, using Equation 5.

$t_{\text {rem }}=\frac{\left(M_{\left(0,05 M_{o}\right)}-M_{\text {prev stage }}\right) 1000}{\ddot{y}}$

where $t_{\text {rem }}$ is the shelf life of the product before its rejection (h); $M_{\left(0,050 M_{0}\right)}$ is the grape weight after losing $5 \%$ of its initial mass $(\mathrm{g}) ; M_{\text {prev stage }}$ is the weight of the grape at the end of the previous stage (g); and $T T_{\left(0^{\circ} \mathrm{Ce} 95 \% \mathrm{RH}\right)}$ is the grape water loss rate per weight unit at the best storage conditions $\left(\mathrm{g} \mathrm{kg}^{-1} \mathrm{~h}^{-1}\right)$.

\section{Results and discussion}

At each stage of the cold chain of Sweet Jubilee table grapes, from the harvest farm field to the cold storage room, it was possible to evaluate the impact of the environment on the estimated shelf life of this fruit. This evaluation was enabled by realistic production routine information, influenced by the available infrastructure and environmental conditions.

\subsection{Ambient and grapes monitoring during cold chain stages}

In general, we were able to observe the uniformity of ambient air conditions inside the packinghouse $\left(26,5 \pm 1,0^{\circ} \mathrm{C}\right.$ e $68 \pm 6 \%$ $\mathrm{RH})$, the cooling tunnel $\left(-2,0 \pm 1,0^{\circ} \mathrm{C}\right.$ e $\left.80 \pm 10 \% \mathrm{RH}\right)$ and the cold storage room $\left(0,5 \pm 0,3^{\circ} \mathrm{C}\right.$ e $\left.90 \pm 8 \% \mathrm{RH}\right)$. In these environments, observed spatial conditions were practically constant and we considered that the positions of the boxes or pallets in these environments did not affect the heterogeneity of the dynamic 
shelf life of the fruits of the same batch. However, this was not observed in the field, where the harvest time has a heterogeneous impact on the grapes' shelf life. The residence time of grapes in each place directly affected their loss of mass and consequently, their estimated shelf life.

The air ambient monitoring of ambient air conditions in the field lasted eight consecutive days. Figure 4a shows average daily temperature and air humidity behavior. Air temperature conditions in the field can be considered uniform throughout the analyzed period, showing only little variations, with a temperature variation of up to $16^{\circ} \mathrm{C}$ between the highest and lowest temperatures for a full day. Relative humidity showed a greater variation, mainly in the first hours of the mornings, probably due to morning dew and field irrigation. The variation of the relative humidity reached $51 \%$ for a full day, but it was held under $60 \%$ during most of the harvesting period.

The worst condition for harvesting fruits and vegetables is at high temperatures and low relative humidity. These conditions intensify the product's metabolic reactions and water loss to the environment, causing weight loss and negatively affecting the fruit's appearance. The water mass loss, or moisture reduction, of the product varies with the integrated coefficient of mass transfer (diffusion and convection), depending on the shape and structure of the fruit, the air movement and the difference of vapor pressure between the fruit surface and the environment. The latter represents the driving force for water loss from the product to the environment, which increases at low relative humidity and high temperatures. In order to prevent water loss, it is necessary to lower the temperature, while reducing the time between harvest and the fruit cooling, increase the relative humidity and reduce air movement (Holcroft, 2015).

During the evaluated harvesting period, more inadequate conditions for grape harvest were observed between 10:00 a.m. and 6:00 p.m., with temperatures surpassing $30{ }^{\circ} \mathrm{C}$ and relative humidity under $50 \%$. It can be corroborated with the grapes water loss rates per weight unit during a full day in the evaluated period of eight days, as shown in Figure $4 \mathrm{~b}$.
The observed values, some of them higher than $1.0 \mathrm{~g} \mathrm{~kg}^{-1} \mathrm{~h}^{-1}$ confirm high water loss for grapes harvested in conditions of high temperature and low humidity. These conditions are present in a large part of the harvest period, which could directly reflect in the quality of the grapes, which may present a series of defects, such as a high incidence of skin cracking. In the rest of the day periods, the rate of water loss remained low and practically constant.

\subsection{Evaluation of grape pallets period of exposure to the ambient conditions during post-harvest processing}

After analyzing the ambient air conditions in each stage of the table grapes cold chain, it was verified the environmental conditions and the period of time that the grapes were exposed to it. With these data, it was possible to evaluate the impacts on the dynamic shelf life of the fruits.

In Figure 5 are shown the temporal temperature and relative humidity conditions to which the afternoon-harvested table grapes that formed the pallets I, II and III were exposed from the field to the cold storage room. The monitored cold chain stages are represented by the following regions of the figures: (i) transport from field to packinghouse, (ii) packinghouse, (iii) cooling tunnel and (iv) cold storage room.

In the same way, Figure 6 shows the temperature and humidity conditions of the cold chain stages from pallets IV and $\mathrm{V}$, formed by morning-harvested grapes. 3

We observed some heterogeneity among the monitored ambient air conditions (temperature and relative humidity) and the period of exposure of the different pallets formed by grapes from a same lot. It can be clearly seen at the cooling tunnel for the grape boxes located at the central region of the pallets. In this spot, the temperature was higher than at the points monitored at the outermost parts of the pallets. In addition, the relative humidity in the central boxes was lower, reaching values lower than $40 \%$ in the beginning of cooling and not exceeding $60 \%$ at the end of this stage. (a)

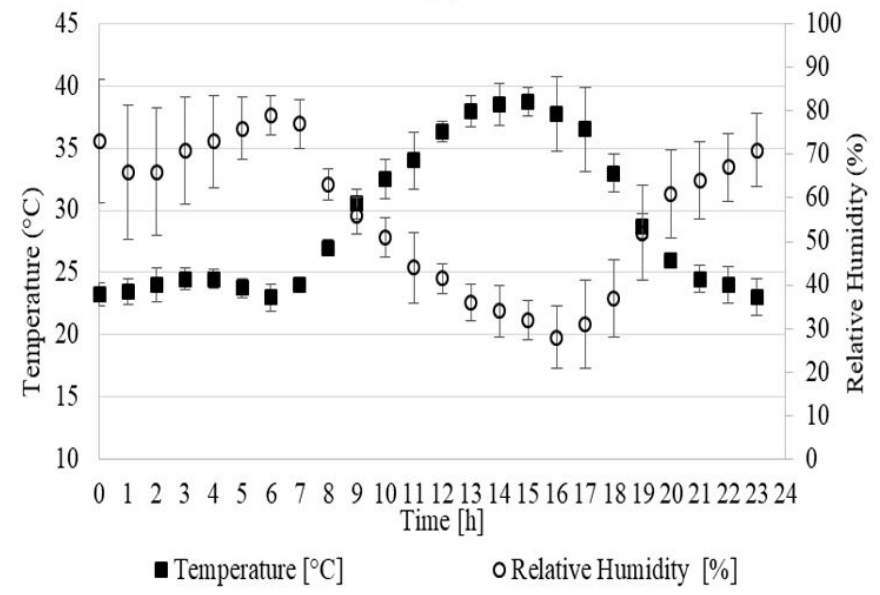

(b)

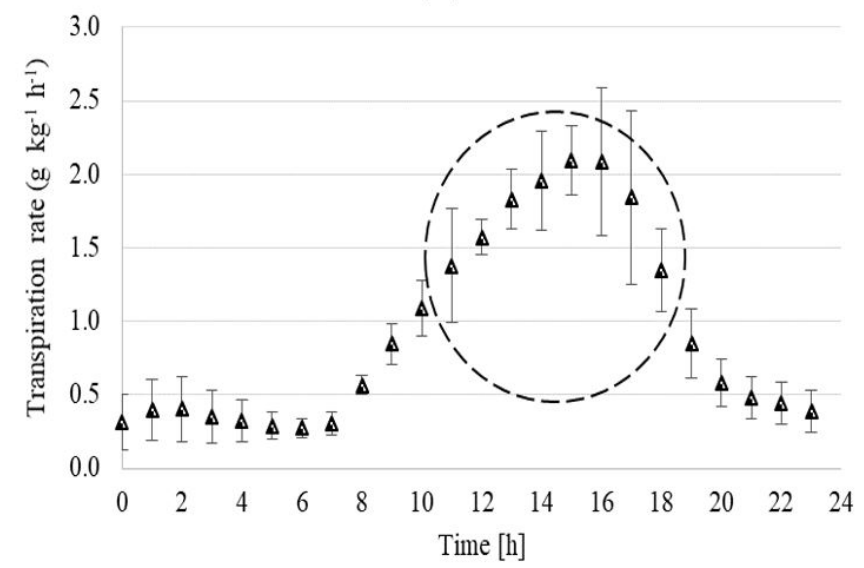

Figure 4. (a) Temperature and relative humidity at the harvest field over $24 \mathrm{~h}$, mean of 8 days; (b) water loss rates per grape weight unit in the field during a full day. 
(a)
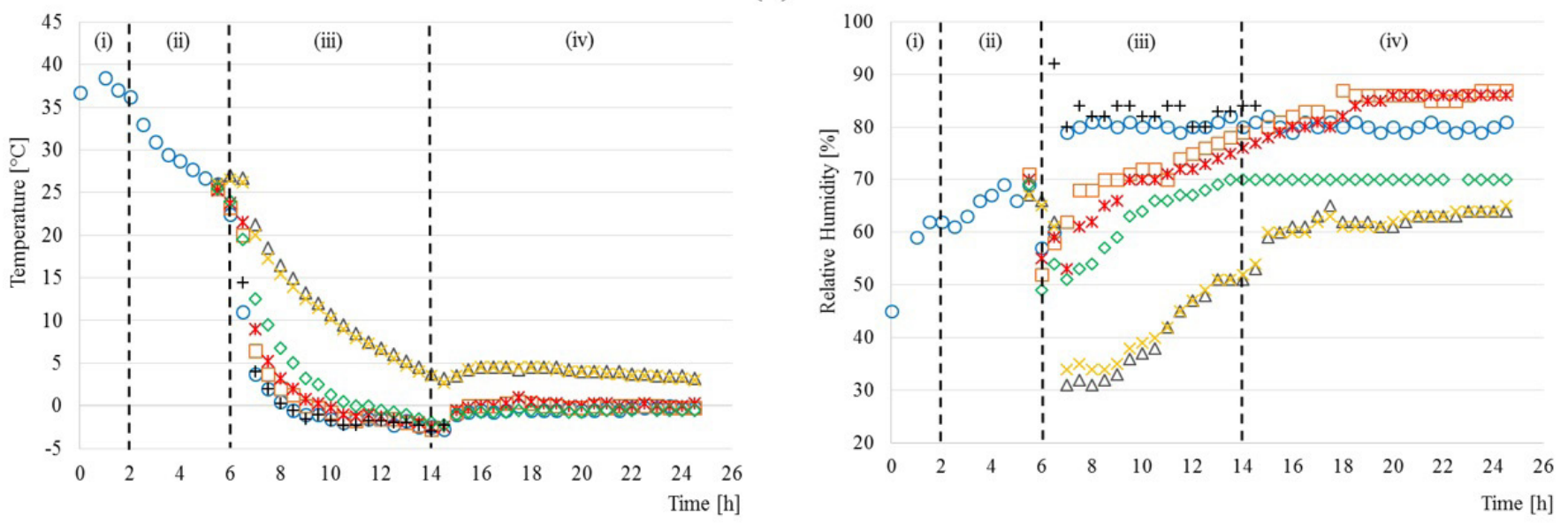

(b)
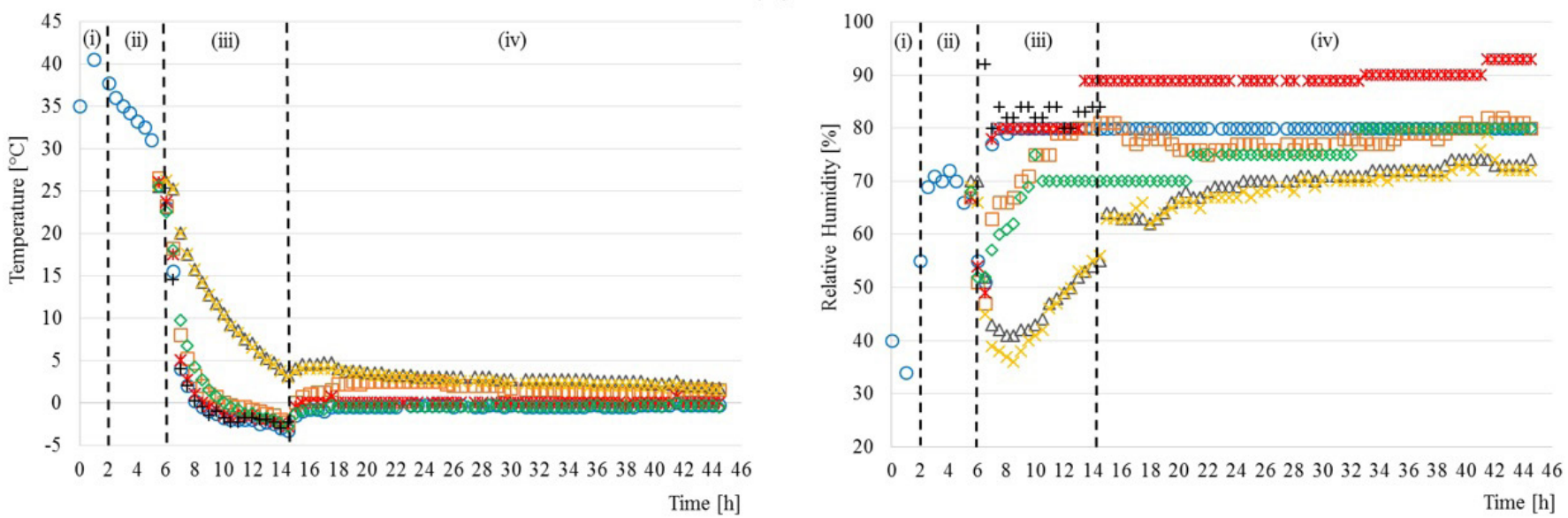

(c)
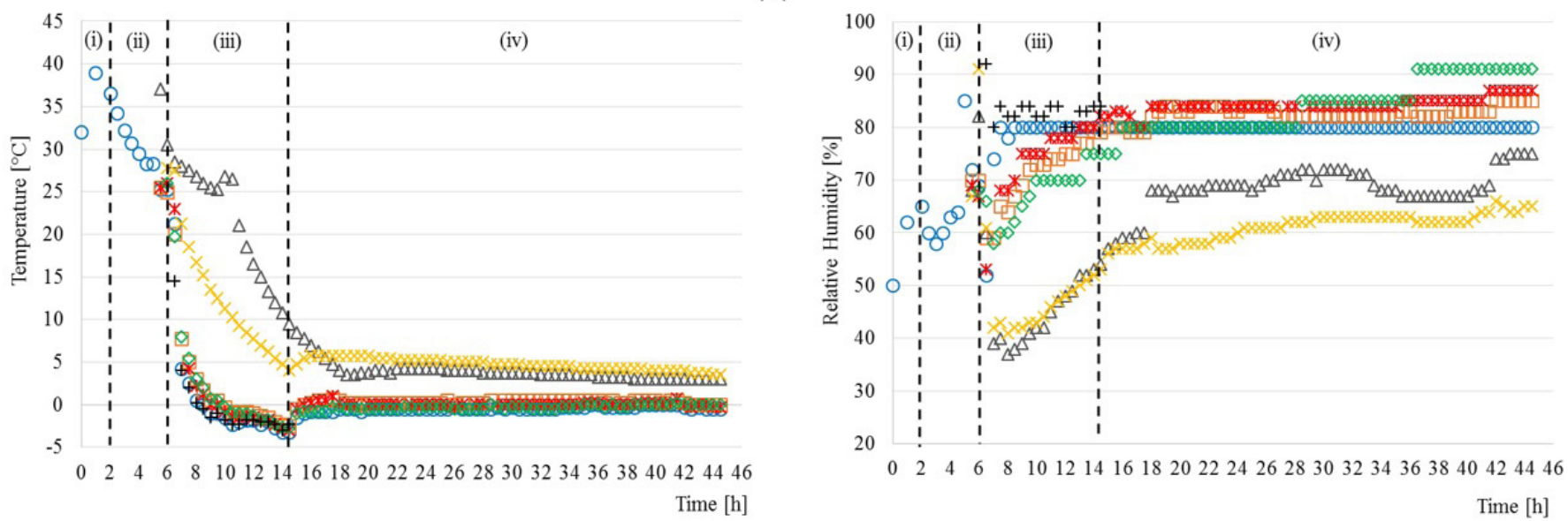

Figure 5. Temperature and humidity conditions over time to which grape pallets (a) I, (b) II and (c) III were exposed along the cold chain stages. $\circ$ Field/ Packing/Position A04; $\square$ Position E04; $\triangle$ Position B11 (inside); $\times$ Position B11 (inside); ${ }^{\star}$ Position C18; $\diamond$ Position D18 and + Tunnel (Environment).

In the cold storage room stage, pallets I, II and III maintained the temperature and humidity heterogeneity among the stacked grape boxes. These pallets were kept at the room for 10,30 and 30 hours, respectively. On the other hand, pallets IV and V showed temperature homogeneity among the boxes after 100h of storage, when they were than marketed. If they stayed longer in the cold room, pallets I, II and III would probably also achieve thermal homogeneity between boxes. This difference in residence time during storage is a crucial parameter for determining fruits dynamic shelf life.

During pallets monitoration, relative humidity usually oscillated and no tendency of homogenization was observed, even after long storage times. It might occurred due to the 
(a)
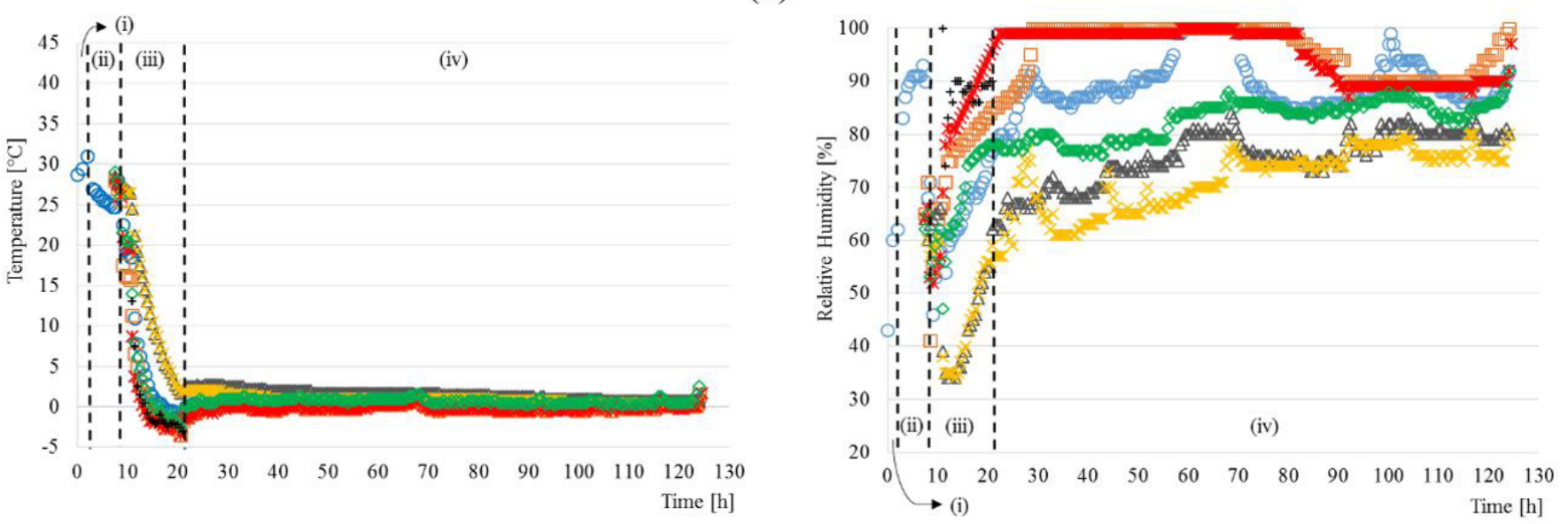

(b)
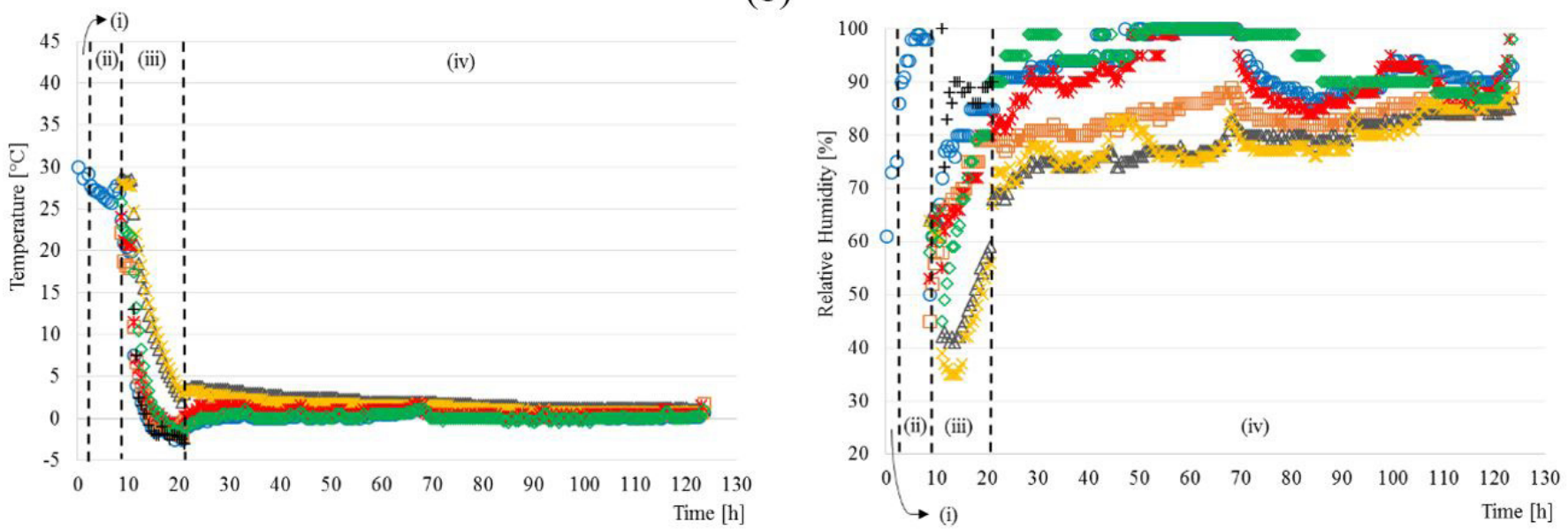

Figure 6. Temperature and humidity conditions over time to which grape pallets (a) IV, and (b) V were exposed along the cold chain stages. $\circ$ Field/ Packing/Position A04; $\square$ Position E04; $\triangle$ Position B11 (inside); $\times$ Position B11 (inside); ${ }^{\star}$ Position C18; $\diamond$ Position D18 and + Tunnel (Environment).

imbalance between the humidification of the nebulizer nozzles and the dehumidification carried out by the refrigeration system, in addition to water condensation on grapes packings when humid air met the cold surface. To overcome this and keep homogenous the humidity, one could use the evaporators operating at small differences between air and the equipment surface temperatures. However, this would result in the need of higher thermal exchange surface areas, and consequently, higher equipment costs. Another strategy could be avoid the confinement of hot and humid air during grapes packaging before pallets cooling in the tunnels.

Regarding the observed heterogeneity among the pallets and the differences inside same pallets, some alternatives could be suggested. The adjustment in ventilation inside cooling tunnel and cold storage room would improve the air distribution and the heat removal from grapes. Improving the cardboard boxes drilling and their positioning during palletization would overcome the difficulty in heat exchange for the inner layers of grapes.

Furthermore, the heterogeneity in grapes loaded on the same pallet can be verified by directly inspecting the fruits. On average, the air temperature within the tunnel reached $-3^{\circ} \mathrm{C}$, while the grape temperatures was around $0{ }^{\circ} \mathrm{C}$. However, the grapes used for sampling were selected from the pallets periphery. Meanwhile, sensors located at the pallets central and inner regions showed temperatures around $3{ }^{\circ} \mathrm{C}$, resulting in grapes with more elevated temperatures at the end of cooling process.

Regarding the harvesting stage, more heterogeneity in the ambient air conditions was observed. The harvest of a single batch of fruits may take all day long, and as seen in Figure 4, the grapes' water loss rates vary with the time of harvesting. Likewise, during the processing of the same batch of grapes, depending on the company operation routine, fruit boxes from a same batch can remain for different periods in the various environments. Therefore, all these monitoring steps and surveys are an important basis for confirming the heterogeneity in the fruit's shelf life, in order to evaluate if it might be significant (for differences greater than 1 day, considering the reality of companies logistics) for considering the application of FEFO methodology.

\subsection{Predictions for grapes dynamic shelf lives}

The period of exposure and the ambient air conditions of the table grape bunches in the first stages of the supply chain 
were associated to the predictive model of reduction of the fruit's dynamic shelf life due to water loss estimates (Equation 4). Figure 7 presents the cumulative predicted weight losses for the grape bunches for each monitored box in pallets I, II and III, in the different and consecutive stages of the supply chain. An initial mass of $500 \mathrm{~g}$ was used to represent a single plastic basket of grape bunches. The reference curve means a grape pallet that have been storage in the best possible cooling condition of $0{ }^{\circ} \mathrm{C}$ and $95 \%$ of relative humidity. Similarly, the dynamic water loss for pallets IV and V are shown in Figure 8.

The results presented confirm the non-homogeneity of table grapes of a same batch quality placed in different pallets. In addition, differences in the weight loss can be observed on a same pallet. These differences are mainly due to the distinct durations of the chain stages for each pallet, combined to the diverse ambient air conditions to which the fruits were exposed. We found that the greatest difference in fruit weight loss in different pallet positions occurred inside the cooling tunnel, where the temperature and relative humidity differences were more expressive. After the storage in the cold room, the differences in weight loss among the fruits positioned near the sensors was practically constant, but with increasing cumulative weight loss over time.

We used the grapes cumulative weight loss measured up to the final monitored stage and the value of the maximum weight loss considered for consumer rejection to estimate their shelf lives, according to Equation 5. The shelf life of a perishable product can be associated with its possible weight loss, under storage reference conditions, before rejection by consumers. Grape rejection is usually determined by its visual aspect and is related to stem darkening and fruit wilting. The weight loss leading to rejection varies with perishable products and with their different varieties. Some authors consider a loss of $5 \%$ in relation to the initial weight as the acceptable quality limit for grapes (Crisosto \& Mitchell, 2002; Holcroft, 2015; Pereira et al., 2017). We used this value to estimate the shelf life of the grape bunches on each monitored pallet (Figure 9), considering the cumulative (a)

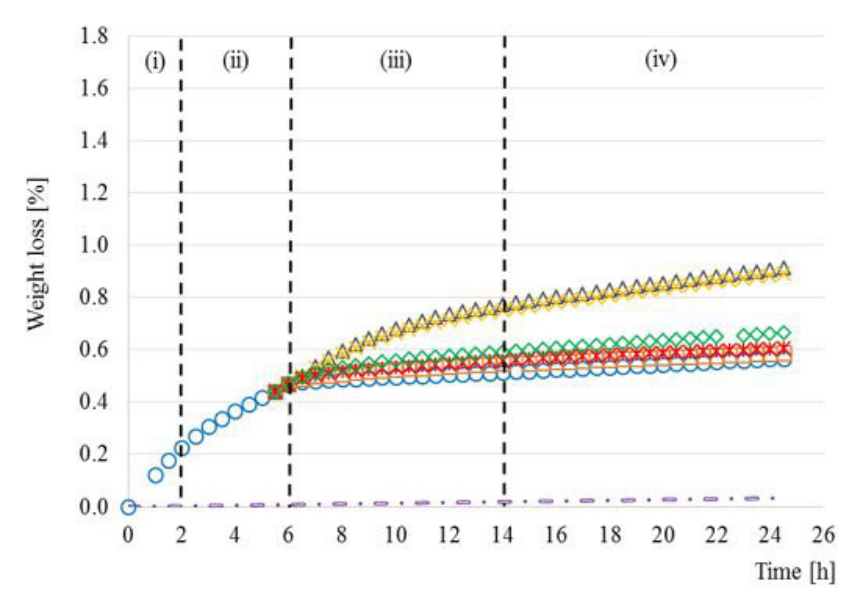

(b)

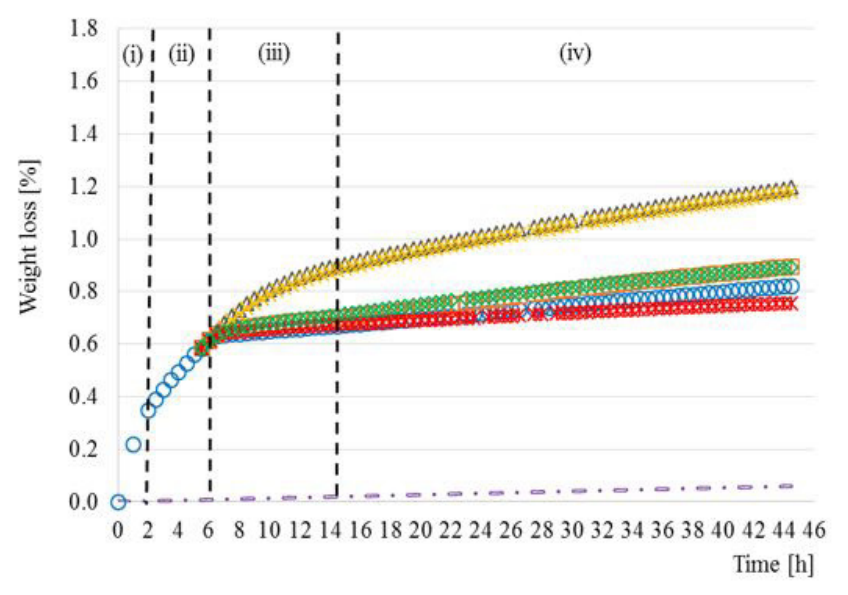

(c)

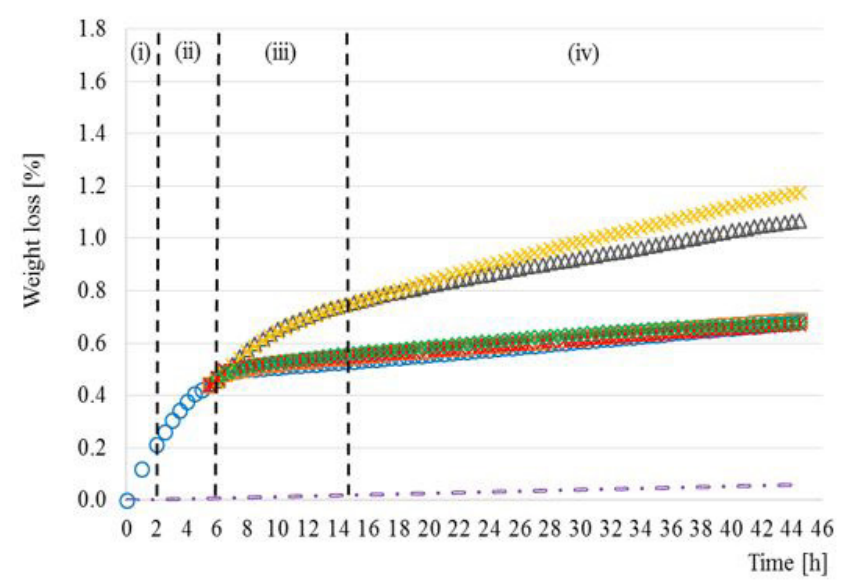

Figure 7. Weight Loss (\%) of grapes bunches on pallets (a) I, (b) II, and (c) III, for each monitored box inside the pallets. Regions (i), (ii), (iii) and (iv) represents the field to packinghouse transport, packinghouse, cooling tunnel, and cold storage room stages, respectively. $\circ$ Field/Packing/Position A04; $\square$ Position E04; $\triangle$ Position B11 (inside); $\times$ Position B11 (inside); ${ }^{\star}$ Position C18; $\diamond$ Position D18; + Tunnel (Environment) and —•— Reference. 
water loss from the harvesting to the expedition stages. The values found for the shelf life are valid for the consideration that from this point the grapes will be disposed in their optimal storage condition $\left(0{ }^{\circ} \mathrm{C}\right.$ and $\left.95 \% \mathrm{RH}\right)$.

It was observed that the shelf life of grape bunches presented different magnitudes among the evaluated pallets and within the same one. The differences between grapes positioned within and in the outer region of a same pallet was up to 16 days in pallets I, II and III, 34 days in pallet IV and 26 days in pallet V. Grapes at the inner positions had a lower shelf life because they showed a higher estimated water loss due to inadequate temperature and humidity conditions. The reference pallet, which was theoretically cooled immediately after harvesting and remained at all stages in optimal conditions, showed a shelf life of more than 150 days.

If applied to the FIFO logistic methodology, as usually occurs in the majority of companies, at first it would be considered that the monitored pallet was homogeneous, that is, that all grape boxes had the same shelf life. Regarding pallets I, II and III, where grapes were harvested and processed at the same time, any of them could be shipped first. However, our results suggest that the shelf life of each pallet (after 24 hours of monitoration) was different, with mean values of 136, 132 and 137 days for pallets I, II and III, respectively. Thus, the application of FEFO logistics would take into account this difference between pallets, where pallet II, with shorter shelf life, should be commercialized first. Similarly, pallets IV and V, which were processed in the following day of the latter ones, also showed distinct shelf lives, with mean values of 126 days for pallet IV and 132 days for pallet $\mathrm{V}$. Thus, it becomes clear that, especially for perishable foods, even for products from a same batch, the sales logistics must take into account not only the moment of processing, but also their entire history of exposure to environmental conditions, from their harvesting until the moment of expedition.

(a)

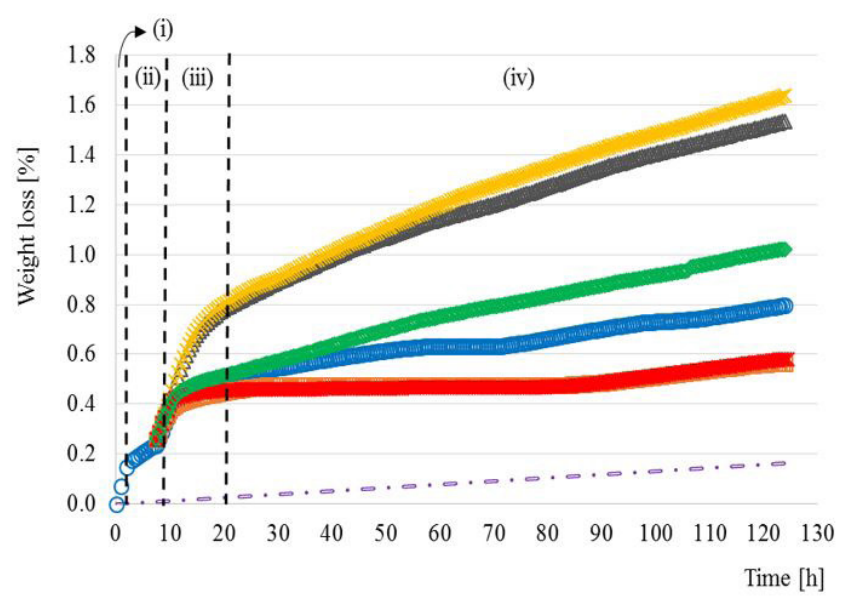

Therefore, at this scenario, we suggest that the commercialization of these products should be efficiently managed considering the distance and the ambient conditions of transportation. Since weight loss is cumulative, poor sale management can lead to a number of problems, such as loss of added value or consumer rejection, depending on the weight lost. Thus, it becomes very clear the importance of monitoring the period of exposure and the ambient conditions throughout the hole supply chain of perishable foods. This would allow determining the dynamic shelf life through the association of a predictive model that might characterize the product and then enable the implementation of intelligent logistics management in the cold chain these products.

It becomes clear now the importance of monitoring time and ambient air conditions that perishable products are exposed since the beginning of their productive chain. In addition to these records providing subsidies that might correct possible bottlenecks in production chain links, it also helps in the application of FEFO management. The monitoring associated

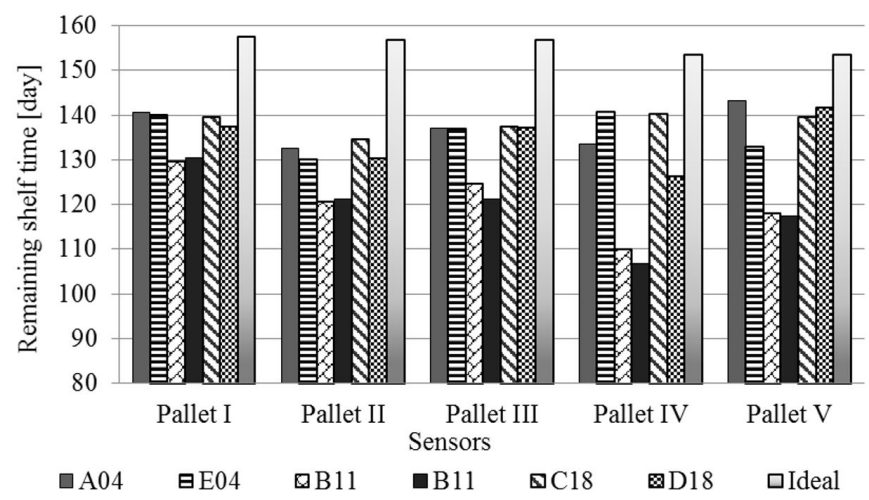

Figure 9. Shelf time for each monitored position in the five evaluated pallets. Ideal represents grapes stored in perfect ambient conditions $\left(0{ }^{\circ} \mathrm{C}\right.$ and $\left.95 \% \mathrm{RH}\right)$ since harvest until the expedition.

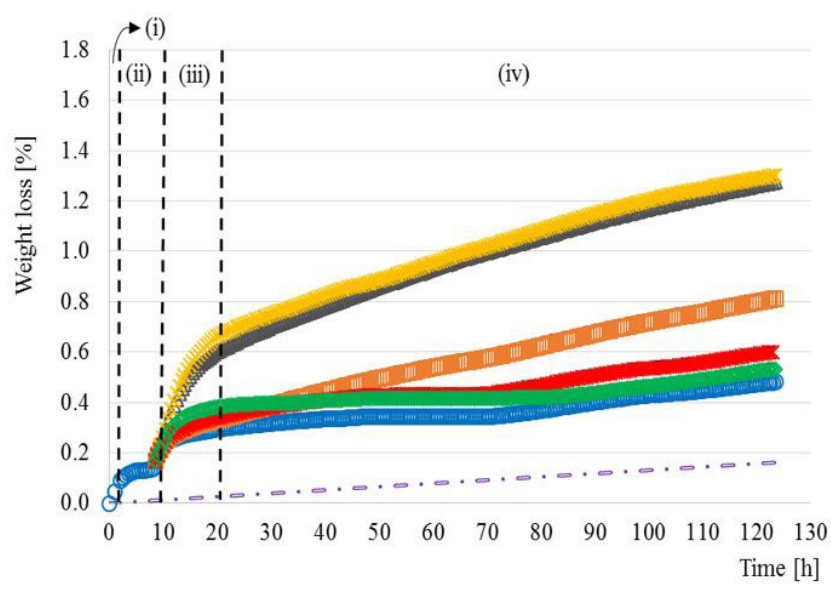

Figure 8. Weight Loss (\%) of grapes bunches on pallets (a) IV, and (b) V, for each monitored box inside the pallets. Regions (i), (ii), (iii) and (iv) represents the field to packinghouse transport, packinghouse, cooling tunnel, and cold storage room stages, respectively. $\circ$ Field/Packing/Position A04; $\square$ Position E04; $\triangle$ Position B11 (inside); $\times$ Position B11 (inside); ${ }^{\star}$ Position C18; $\diamond$ Position D18; + Tunnel (Environment) and —•— Reference. 
with a predictive model that characterizes the product would be able to determine how much of its shelf life the product has already lost up to that moment and predict how much it would lose by estimating the time and ambient air conditions that it will be exposed in the next links. In that way, one could check if that product would reach the next link with acceptable quality. In summary, this whole scenario will depend on the environmental exposure history, providing intelligent logistics management in the cold chain of perishable products.

\section{Conclusion}

In this study, high heterogeneity in ambient conditions was observed during grapes cold chain, especially inside the cooling tunnel, in which the center of the pallets showed more elevated temperatures and lower relative humidity when compared with the boxes of grapes located at the outer side of the pallets. It was found that fruits from the same batch stacked in different pallets and grape boxes in a same pallet were subjected to varied water loss rates. In addition, a high variation in the shelf life between pallets and between boxes on the same pallet was observed. We consider that the predictive model used was satisfactory to present differences in shelflife of grapes that may have been subjected to different exposure conditions, taking into account two parameters of fundamental importance in the processing of perishable products, which are the temperature and relative humidity of ambient air. Thus, we could ascertain that the shelf life of perishable products is dependent on environmental conditions and period of exposure, becoming dynamic due to non-homogeneity of factors during companies routines. Because of this, the shelf life printed on packaging labels becomes questionable, as well as expiration dates.

The use of the FEFO methodology instead of FIFO is a consequence of the observed heterogeneity in products of same batch. Thus, the logistics strategies must be reconsidered, since the importance is no longer the arrival order (FIFO), but the historical of the environmental conditions and the product exposure time. This information must be taken into account in the commercialization process, where products final price and distribution distance will be directly related to their quality.

\section{Acknowledgements}

The authors would like to thank FAPESP for its financial support, BT9 for providing Xsense technology and Espaço da Escrita - Pró-Reitoria de Pesquisa - UNICAMP - for the language services provided.

\section{References}

Antoine, C. (1888). Tensions des vapeurs; nouvelle relation entre les tensions et les temperatures. Comptes Rendus Des Séances de l'Académie Des Sciences, 107, 681-684.

Aung, M. M., \& Chang, Y. S. (2014). Temperature management for the quality assurance of a perishable food supply chain. Food Control, 40, 198-207. http://dx.doi.org/10.1016/j.foodcont.2013.11.016.

Badia-Melis, R., McCarthy, U., Ruiz-Garcia, L., Garcia-Hierro, J., \& Robla Villalba, J. I. (2018). New trends in cold chain monitoring applications - A review. Food Control, 86, 170-182. http://dx.doi. org/10.1016/j.foodcont.2017.11.022.
Benítez, R. O. (2018). Losses and food waste in Latin America and the Caribbean. Rome, Italy: FAO. Retrieved from http://www.fao.org/ americas/noticias/ver/en/c/239392/

BT9. (2018). Fresh produce. Retrieved from http://www.bt9-tech.com/ food-supply-chain/

Chitarra, M. I. F., \& Chitarra, A. B. (2005). Pós-colheita de frutas e hortaliças: fisiologia e manuseio (2nd ed.). Lavras: Universidade Federal de Lavras.

Crisosto, C. H., \& Mitchell, F. G. (2002). Postharvest handling systems: small fruits. Postaharvest Technology of Horticultural Crops., 3, 357-363.

Cuiñas, I., Newman, R., Trebar, M., Catarinucci, L., \& Melcon, A. A. (2014). RFID-based traceability along the food-production chain. IEEE Antennas \& Propagation Magazine, 56(2), 196-207. http:// dx.doi.org/10.1109/MAP.2014.6837090.

EMBRAPA. (2018). Food loss and waste. Brasília: Embrapa. Retrieved from https://www.embrapa.br/tema-perdas-e-desperdicio-dealimentos/sobre-o-tema

Holcroft, D. (2015). Water relations in harvested fresh produce. La Pine, OR: The Postharvest Education Foundation (PEF).

Jedermann, R., Nicometo, M., Uysal, I., \& Lang, W. (2014a). Reducing food losses by intelligent food logistics. Philosophical Transactions of the Royal Society A: Mathematical, Physical and Engineering Sciences, 372(2017), 20130302-20130302. http://doi.org/10.1098/ rsta.2013.0302

Jedermann, R., Praeger, U., Geyer, M., \& Lang, W. (2014b). Remote quality monitoring in the banana chain. Philosophical Transactions of the Royal Society A: Mathematical, Physical and Engineering Sciences, 372(2017), 20130303-20130303. http://doi.org/10.1098/ rsta.2013.0303

Jedermann, R., Ruiz-Garcia, L., \& Lang, W. (2009). Spatial temperature profiling by semi-passive RFID loggers for perishable food transportation. Computers and Electronics in Agriculture, 65(2), 145-154. http://dx.doi.org/10.1016/j. compag.2008.08.006.

Kim, W. R., Aung, M. M., Chang, Y. S., \& Makatsoris, C. (2015). Freshness Gauge based cold storage management: A method for adjusting temperature and humidity levels for food quality. Food Control, 47, 510-519. http://dx.doi.org/10.1016/j. foodcont.2014.07.051.

Leonardi, C., Baille, A., \& Guichard, S. (1999). Effects of fruit characteristics and climatic conditions on tomato transpiration in a greenhouse. Horticultural Science and Biotechnology, 74(6), 748-756. http:// dx.doi.org/10.1080/14620316.1999.11511183.

Nunes, M. C. N., Nicometo, M., Emond, J. P., Melis, R. B., \& Uysal, I. (2014). Improvement in fresh fruit and vegetable logistics quality: berry logistics field studies. Philosophical Transactions of the Royal Society A: Mathematical, Physical and Engineering Sciences, 372(2017), 20130307-20130307. http://doi.org/10.1098/rsta.2013.0307

Pereira, E., Silva, R. G. B., Spagnol, W. A., \& Silveira, V. Jr. (2017). Water loss in table grapes: model development and validation under dynamic storage conditions. Food Science and Technology, 38(3), 473-479. http://dx.doi.org/10.1590/1678-457x.08817.

Ruiz-Garcia, L., \& Lunadei, L. (2010). Monitoring cold chain logistics by means of RFID. Sustainable Radio Frequency Identification Solutions, 2, 37-50. http://dx.doi.org/10.5772/8006

Sarntichartsak, P., \& Thepa, S. (2013). Modeling and experimental study on the performance of an inverter air conditioner using R-410A with evaporatively cooled condenser. ATE, 51(1-2), 597-610. http:// dx.doi.org/10.1016/j.applthermaleng.2012.08.063. 
Sastry, S. K., Baird, C. D., \& Buffington, D. E. (1978). Transpiration rates of certain fruits and vegetables. ASHRAE Transactions, 84(1), 237-254.

Sastry, S. K., \& Buffington, D. E. (1983). Transpiration rates of stored perishable commodities: a mathematical model and experiments on tomatoes. International Journal of Refrigeration, 6(2), 84-96. http://dx.doi.org/10.1016/0140-7007(83)90050-6.

United Nations. (2015). Transforming our world: the 2030 Agenda for Sustainable Development. São Francisco, CA: UN. Retrieved from https://sustainabledevelopment.un.org/post2015/ transformingourworld
Todd, E. C. D. (2017). Foodborne disease and food control in the Gulf States. Food Control, 73, 341-366. http://dx.doi.org/10.1016/j. foodcont.2016.08.024 PMid:32288324.

WRI Brasil (2017, September 26). A receipt to reduce food loss and waste. WRI Brasil. Retrieved from https://wribrasil.org.br/en/ blog/2017/09/receipt-reduce-food-loss-and-waste

Zou, Z., Chen, Q., Uysal, I., \& Zheng, L. (2014). Radio frequency identification enabled wireless sensing for intelligent food logistics. Philosophical Transactions of the Royal Society A: Mathematical, Physical and Engineering Sciences, 372(2017), 20140209. http://doi. org/10.1098/rsta.2013.0313 